\title{
Influence of entrainment of CCN on microphysical properties of warm cumulus
}

\author{
J. W. B. Derksen, G.-J. H. Roelofs, and T. Röckmann \\ Institute for Marine and Atmospheric Research Utrecht (IMAU), Utrecht University, Utrecht, The Netherlands \\ Received: 3 February 2009 - Published in Atmos. Chem. Phys. Discuss.: 2 April 2009 \\ Revised: 9 July 2009 - Accepted: 14 July 2009 - Published: 20 August 2009
}

\begin{abstract}
We use a 1-D cloud model with explicit microphysics and a binned representation of the aerosol size distribution to investigate the influence of entrainment of cloud condensation nuclei $(\mathrm{CCN})$ on the microphysical development of warm cumulus clouds. For a more realistic representation of cloud drop spectral width, the model separates droplets that grow on aerosol that is initially present in the cloud from droplets growing on entrained aerosol. Model results are compared with observations of trade wind cumulus microphysics from the Rain in Cumulus over the Ocean experiment (RICO, 2004-2005). The results indicate that CCN are entrained throughout the entire cloud depth, and inside the cloud part of these may be activated. Compared to a simulation where entrainment of ambient $\mathrm{CCN}$ is neglected this leads to higher cloud droplet number concentrations (CDNC) and a continuous presence of droplets in the range smaller than $\sim 5 \mu \mathrm{m}$ that is consistent with the observations. Cloud dynamics are sensitive to the entrainment parameter as well as to the applied initial vertical velocity, as expressed by the liquid water content and cloud top height. However, simulated cloud drop spectra remain relatively unaffected for the specific conditions during RICO.
\end{abstract}

\section{Introduction}

Anthropogenic emissions of primary aerosol particles and aerosol precursors (sulfur dioxide, non-methane higher hydrocarbons, nitrogen oxides, soot) have increased atmospheric aerosol concentrations substantially since preindustrial times (e.g., Charlson et al., 1992; Solomon et al., 2007). Aerosols act as cloud condensation nuclei, and

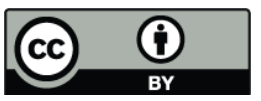

Correspondence to: J. W. B. Derksen (j.w.b.derksen@uu.nl) the increasing aerosol abundance and changing chemical composition affect climate through the so-called aerosol indirect effects. In the first indirect effect, an increase of aerosol particles leads to a higher cloud droplet number concentration, a smaller average drop radius and a larger optical thickness (Twomey, 1977). In the second indirect effect, the efficiency of precipitation formation decreases because of the smaller drop size, and the cloud lifetime increases (Albrecht, 1989).

The cloud drop number concentration (CDNC) is a crucial parameter for both effects (Lohmann and Feichter, 2005), because it is associated with the average droplet size. Therefore, much research effort has been invested in the development of parameterizations for CDNC that can be used in general circulation models (e.g., Hänel, 1987; Fountoukis and Nenes, 2005). Since the initial CDNC is determined directly at cloud base, understanding how meteorological characteristics and aerosol properties influence aerosol activation at the cloud base has received a lot of attention (e.g., Kulmala et al., 1993). In the second place, the distribution of the liquid water with droplet size further influences both scattering and precipitation formation processes (e.g., Roelofs and Jongen, 2004; Roelofs and Kamphuis, 2009). A model study of cloud microphysics therefore requires a realistic representation of both CDNC and the drop size distribution.

During adiabatic cloud development the liquid water content (LWC) evolves adiabatically with height and, when neglecting collision/coalescence between droplets, CDNC remains constant throughout the cloud depth (Pruppacher and Klett, 1978). However, many observed clouds develop in a sub-adiabatic manner, with continuous entrainment of surrounding subsaturated air into the cloud, resulting in smaller LWC and CDNC than their adiabatic values (e.g., Penner and Chuang, 1999; Gerber et al., 2005; Meskhidze et al., 2005). Simultaneously, the entrained air contains unactivated aerosol. During mixing with cloudy air these are exposed

Published by Copernicus Publications on behalf of the European Geosciences Union. 
to supersaturation conditions and may partly activate. Thus, small and recently activated droplets are added continuously to the cloud air and this results in a broadening of the drop size distribution.

The process of mixing between clouds and their environment is complicated and not fully understood. At least three major questions are associated with the mixing dynamics:

1) What is the source of the entrained air? Two main hypotheses exist: entrainment at the top of the cloud, observed by Paluch (1979), and lateral entrainment, observed by Raga et al. (1990) and Hicks et al. (1990). Heus et al. (2008) showed that for trade wind cumuli observed during the Barbados Oceanographic and Meteorological Experiment (BOMEX; Holland and Rasmusson, 1973), which is the relevant type of clouds for this study, the lateral entrainment process is dominant.

2) What is the strength of entrainment, i.e. how much air is entrained into the cloud? Warner (1970) compared observations with an entraining-plume model, assuming that the fractional rate of entrainment, $\mu$, is related to the parcel radius, $R$, as $\mu=\frac{\alpha}{R}$, where $\alpha$ is an empirical coefficient set at 0.2. This parameterization has been adapted in many studies, though the value for this entrainment parameter is rather uncertain. Values from 0.1 up to 0.6 are derived from observations and applied in different model studies (Su et al., 1998; Roesner et al., 1990; Pruppacher and Klett, 1978; Roelofs and Jongen, 2004). Siebesma et al. (2003) suggested that, based on a LES study, the entrainment rate decreases linearly with height: $\mu \simeq 1 / z$.

3) Is the mixing process homogeneous or inhomogeneous? $\mathrm{Su}$ et al. (1998) give a nice overview of the definitions: in homogeneous mixing the typical time scale of the mixing between the cloud air and the environmental air, through turbulence, is small compared to the typical time scale for condensational growth of the entrained particles. In that case, the entrained drops and the drops initially present in the cloud are subjected to the same saturation. In inhomogeneous mixing, on the other hand, the mixing time scale is larger than the time scale for condensational growth, and different droplets encounter different saturation conditions. Both mixing processes have been observed (Paluch, 1986; Blyth and Latham, 1990; Hicks et al., 1990; Burnet and Brenguier, 2007).

The microphysical evolution of drops in an entraining cloud with inhomogeneous mixing can be represented adequately only in a 2-D or 3-D cloud resolving model with detailed representations of turbulent mixing and aerosol microphysics, but these are computationally expensive. Studies which focus on boundary layer dynamics therefore often omit explicit aerosol microphysics (Siebesma and Cui- jpers, 1995; Stevens et al., 2001). The 3-D Model with binmicrophysics presented by Leroy et al. $(2007,2009)$ uses a time resolution in the order of second(s). Such relatively low time resolution may result in inaccurate simulation of microphysical processes, such as condensation and droplet activation, since their time scales are in the order of $0.1 \mathrm{~s}$. Therefore, a relative crude time resolution may result in an inaccurate estimate of the CDNC. Another approach has been the use of parcel trajectory ensembles, combined with a 3-D or LES model (Erlick et al., 2005; Lee et al., 2008). Disadvantage of the approaches using parcel models is that the parcels do not interact with each other and are often considered without entrainment of ambient $\mathrm{CCN}$. In dedicated parcel model studies, where the cloud is represented as a homogeneous air mass, detailed microphysical calculations are more feasible (e.g., Kreidenweis et al., 2003). Mixing of entrained air in a cloud parcel model is by definition homogeneous. In order to preserve the information held by the simulated drop size distribution it is necessary, however, to separate the representations of larger, older cloud drops and smaller entrained particles.

It is not our aim to study the process of mixing in cumuli itself, but the influence of entrainment on cloud dynamical and microphysical parameters, especially the droplet spectra. We use a one-dimensional (1-D) cloud column model that contains a binned representation of aerosol. It simulates aerosol activation, condensational growth and evaporation based on Köhler microphysics. The representation of the drop size distribution in the model enables a separate evaluation of entrained drops and mature cloud drops, as described in more detail in Sect. 2. Note that the 1-D model does not represent inhomogeneous mixing, tilting of the cloud and separation of the updraft from the downdraft regions, but vertical interaction (for instance rain droplets sweeping through the column) is represented. The model is applied to the simulation of a typical trade cumulus cloud observed during RICO (Rain in Cumulus over the Ocean; Rauber et al., 2007). The measurement campaign was carried out during December 2004 January 2005 and was located near the islands of Antigua and Barbuda, an area under influence of persistent trade winds. Simulated vertical profiles of cloud water, CDNC, average cloud drop size and cloud drop size distribution are evaluated, and their sensitivity to dynamical parameters (entrainment efficiency, updraft velocity) is examined. Section 3 describes the relevant observations from RICO. In Sect. 4 the results of the study are presented and discussed, and Sect. 5 presents the conclusions.

\section{Model description}

We use a one-dimensional circular axisymmetric cloud model (Ogura and Takahashi, 1971; Takahashi, 1976). We implemented the detailed microphysical module applied in the cloud parcel model by Roelofs and Jongen (2004). In 
addition, the model now incorporates a detailed representation of entrained cloud condensation nuclei $(\mathrm{CCN})$ and their evolution. Ice formation and radiative transfer are not simulated.

The model simulates a vertical cloud column with a radius of $300 \mathrm{~m}$. Around this column a passive circular concentric column is present, representing the cloud environment, where all properties are kept constant. The domain ranges from 0 to $4 \mathrm{~km}$ altitude with a vertical grid distance of $100 \mathrm{~m}$ and a time resolution of $0.1 \mathrm{~s}$. Upper and lower boundaries are closed and associated quantities are kept constant.

Vertical motions of air are suppressed at the upper and lower boundaries and are controlled by buoyancy and drag in the interior. Exchange between the cloud and the environment occurs in two ways. In the first place, convergence and divergence in the computed vertical velocity field in the cloudy column drive in- and outflow through the lateral boundary. In the second place lateral mixing occurs. The strength of lateral entrainment is set through the fractional entrainment rate, $|w| \frac{\alpha}{R}$, where $w$ is the vertical velocity, $R$ is the radius of the cloud and $\frac{\alpha}{R}$ is the entrainment parameter. The fractional entrainment rate determines the volume fraction of a model grid space which is exchanged with the environment every time step. In our study we use a value of 0.4 for $\alpha$, unless stated otherwise. This is consistent with Gerber et al. (2008) who showed that during RICO on 11 January (the data used in this study is observed on this date, see Sect. 3 for details) the average fractional entrainment, $\frac{\alpha}{R}$, for the lower $1.5 \mathrm{~km}$ is $1.3 \mathrm{~km}^{-1}$ with an observed mean width of the towering cloud tops (i.e., $2 R$ ) of $550 \mathrm{~m}$. Lateral entrainment decreases gradients between cloudy and ambient air.

Aerosols are represented by a discrete size distribution, that ranges from 0.002 to $5 \mu \mathrm{m}$ and is divided in 50 bins. Each size bin has a continuously modified wet radius associated with it, that is modified through condensation or evaporation. Aerosol activation and condensation/evaporation of water are calculated according to the Köhler equations, parameterized according to Hänel (1987). The collisioncoalescence process is parameterized according to Jacobson (1998). Drops formed through collision-coalescence are transferred to a discrete size distribution with 50 bins, ranging from 0.1 to $2000 \mu \mathrm{m}$. These droplets are also subject to condensation and evaporation. They may be removed from the cloud as rain due to their relatively large fall velocities.

During cloud development, ambient $\mathrm{CCN}$ are entrained into the cloud and a part becomes activated after mixing with the supersaturated cloud air. That implies that at any moment, besides older larger droplets, small droplets with a size of the order of several micrometers are present at any level within the cloud. To optimally represent both the droplets formed during the cloud onset and the droplets growing on entrained particles, their evolution has to be considered separately, i.e. in separate droplets size distributions. However, in order to keep the computational time limited the different distributions must be combined at specific instants during the simulation. The time interval between different averaging events, $t_{m}$, must reflect the time for condensational growth from their critical size to typical cloud drop sizes. This period of time depends on the supersaturation, i.e. the speed of condensational growth. During simulations the typical supersaturation is $0.4 \%$. At this supersaturation, a droplet of $1 \mu \mathrm{m}$ needs $90 \mathrm{~s}$ to grow to a size of $8 \mu \mathrm{m}$ and $300 \mathrm{~s}$ to grow to $15 \mu \mathrm{m}$.

In the present version, the model contains four different aerosol/drop size distributions. One distribution is assigned to represent the aerosol/droplets initially present in the column and another distribution represents the most recently entrained CCN. The remaining distributions represent previously entrained particles. In a sensitivity study, we obtained good results for $t_{m}=100 \mathrm{~s}$. This means that every $100 \mathrm{~s}$ each distribution is shifted to the next, and $300 \mathrm{~s}$ after their entrainment, particles are combined with the distribution that carries the initial cloud aerosol.

\section{RICO and data description}

The Rain In Cumulus over the Ocean (RICO) field campaign took place during November 2004-January 2005 off the Caribbean Islands of Antigua and Barbuda. The area is characterized during this period by shallow trade wind cumuli, most frequently topping at $800 \mathrm{hPa}$ under the influence of an inversion layer. Convection reaching up to $700 \mathrm{hPa}$ and higher has been observed.

A goal of the campaign was to gain insight in the rain initiation processes within shallow maritime cumulus. Therefore, cloud properties such as LWC and droplet size distributions were measured. Also vertical temperature and humidity profiles were measured with dropsondes. $\mathrm{CCN}$ measurements were done during low altitude circles at $100 \mathrm{~m}$ height. Clouds were measured by the $\mathrm{C} 130$ aircraft at 5 different height levels $(800,1000,1200,1500$ and $1650 \mathrm{~m})$ at $1 \mathrm{~Hz}$, corresponding to approximately $100 \mathrm{~m}$ flight distance. We focus on data measured on 11 January, which was characterized by lower drizzle concentrations than other RICO days (Gerber et al., 2008). For these circumstances, effects of entrainment can be studied without influence of LWC depletion by precipitation.

We applied two criteria to filter the data: 1) The measured LWC is larger than $0.05 \mathrm{~g} / \mathrm{kg}$ and 2) the vertical velocity is positive. This excludes cloudless regions and in-cloud parts dominated by downdrafts and emphasizes the cloud cores simulated by our model. The resulting data set is an ensemble of many different clouds, in a different stage of development and measured at a different location, both geometrically as well as with respect to the position within a cloud. We remark that the observed $1650 \mathrm{~m}$ level only consists of two data points. 
To compare model results with observations, the same criteria are used to sample the model domain. For both simulated and observed data sets we calculated median values for LWC, mean radius $\left(r_{m}\right)$ and CDNC, as well as for the total size distributions. The observed and simulated data sets are different in that sense that the observations reflect an ensemble of "snap-shots" of many different clouds, whereas the model reflects one complete cloud evolution of an average cloud. We will investigate if the modeled cloud does represent the average evolution of the RICO ensemble.

\section{Results and discussion}

\subsection{Model initialization}

Sonde data from 14.40 UTC (see Fig. 1) were used to initialize the vertical temperature and specific humidity profiles in the model. The sounding reflects a dry adiabatic lapse rate $(\sim-10 \mathrm{~K} / \mathrm{km})$ from the surface up to $600 \mathrm{~m}$ height, the location of the lifting condensation level, and a lapse rate of $-7 \mathrm{~K} / \mathrm{km}$ from $600 \mathrm{~m}$ to $1700 \mathrm{~m}$, which is conditionally unstable. An inversion layer was located at $1700 \mathrm{~m}$. Small scale vertical variations can not be represented due to the relative coarse model resolution. Hence, we used the observed lapse rates as input. Surface temperature is initialized at $298.5 \mathrm{~K}$. We remark that the observed horizontal variability of relative humidity (RH) ranges up to ten percent, indicating a significant spatial variability of the atmospheric conditions under which the cumulus clouds are formed.

The average vertical velocity of the data ensemble at $800 \mathrm{~m}$ altitude, the approximate cloud base height, is $1.18 \mathrm{~m} / \mathrm{s}$. Generally, larger updraft velocities are associated with larger values for LWC: increasing the LWC threshold of the ensemble from $0.05 \mathrm{~g} / \mathrm{kg}$ to $0.1 \mathrm{~g} / \mathrm{kg}$ results in an average vertical velocity of $1.42 \mathrm{~m} / \mathrm{s}$, and $0.2 \mathrm{~g} / \mathrm{kg}$ results in $2.27 \mathrm{~m} / \mathrm{s}$. We assumed an initial vertical updraft velocity below the cloud base of $1.5 \mathrm{~m} / \mathrm{s}$, to be able to represent also more vigorous clouds. We investigated the sensitivity of the simulated cloud characteristics for variations in the updraft velocity.

The aerosol size distribution is initialized based on daily averaged values of CCN measurements (see Hudson and Mishra, 2007 for details). A three-modal lognormal distribution is fitted to the observations (see Table 1). Hudson and Mishra (2007) found that CCN concentrations showed little variability during each low altitude flight, though concentrations increased during the day. Gerber et al. (2008) found that the $\mathrm{CCN}$ concentration at $1.5 \%$ supersaturation was approximately constant with height, indicating a well mixed boundary layer. Therefore, we took an aerosol scaleheight of $8000 \mathrm{~m}$, resulting in a near constant CCN concentration throughout the boundary layer. Peter et al. (2008) showed that most aerosol larger than $0.2 \mu \mathrm{m}$ consisted of sea salt, but that aerosol smaller than $0.2 \mu \mathrm{m}$ consisted mostly of am-

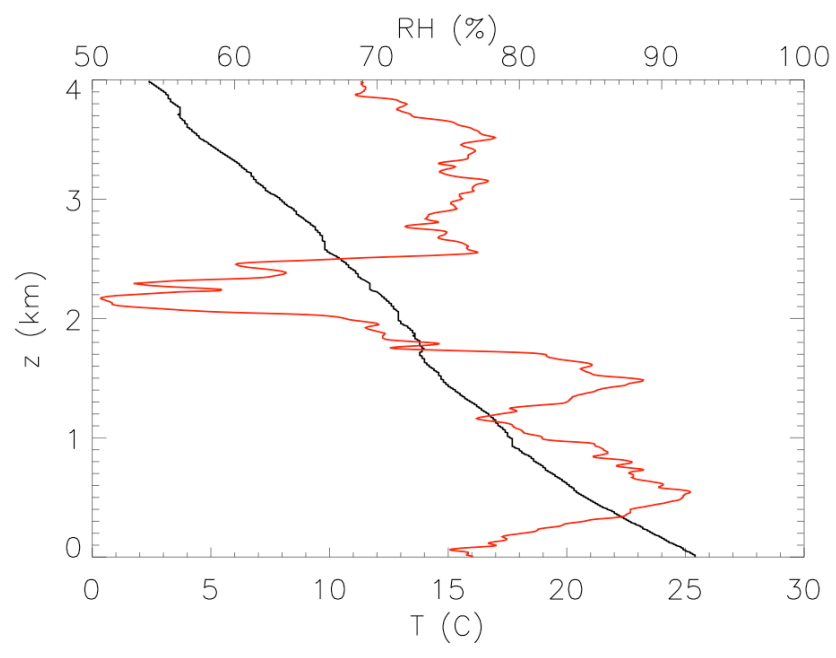

Fig. 1. Vertical profiles of temperature (black) and relative humidity (red), from drop sonde.

monium sulphate. For computational reasons we assume all aerosol to consist of sea salt. This assumption can lead to a slightly smaller cutoff radius and thus larger CDNC, but the differences are insignificant compared to the effect of spatial variabilities in humidity mentioned above. The environmental column is initialized with the same aerosol size distribution and vertical profile and assumed to be constant throughout a simulation.

\subsection{Analysis of the base case}

Figure 2 shows the simulated profiles of LWC and its sensitivity for humidity, of CDNC and of the median radius, together with the observations. The observed data ensemble at $1650 \mathrm{~m}$ altitude consists of two measurements. Therefore the mean of the observations is shown at this height, since the median would be one of both measurements. The vertical profile of the simulated median LWC is qualitatively similar to the observed profile. The median increases from the cloud base up to $\sim 1.2 \mathrm{~km}$ altitude. Between 1200 and $1500 \mathrm{~m}$ altitude the model predicts a decrease. No observations are available at these heights to verify this result. Just below cloud top the simulated median value increases again in agreement with the observations. Similar LWC profiles were found in other trade wind cumulus studies (e.g., $\mathrm{Lu}$ et al., 2003). The LWC profile reflects the RH profile, with local maxima of $\sim 90 \%$ at 500 and $1500 \mathrm{~m}$ altitude (see Fig. 1). The cloud entrains increasingly moist air above $1200 \mathrm{~m}$, leading to an increasing saturation level in the cloud which supports condensation of water vapor.

The model underestimates the median LWC throughout the cloud depth (up to $50 \%$ below the cloud top), as well as the range in observed LWC values. To investigate the sensitivity of LWC for humidity, we performed two additional 

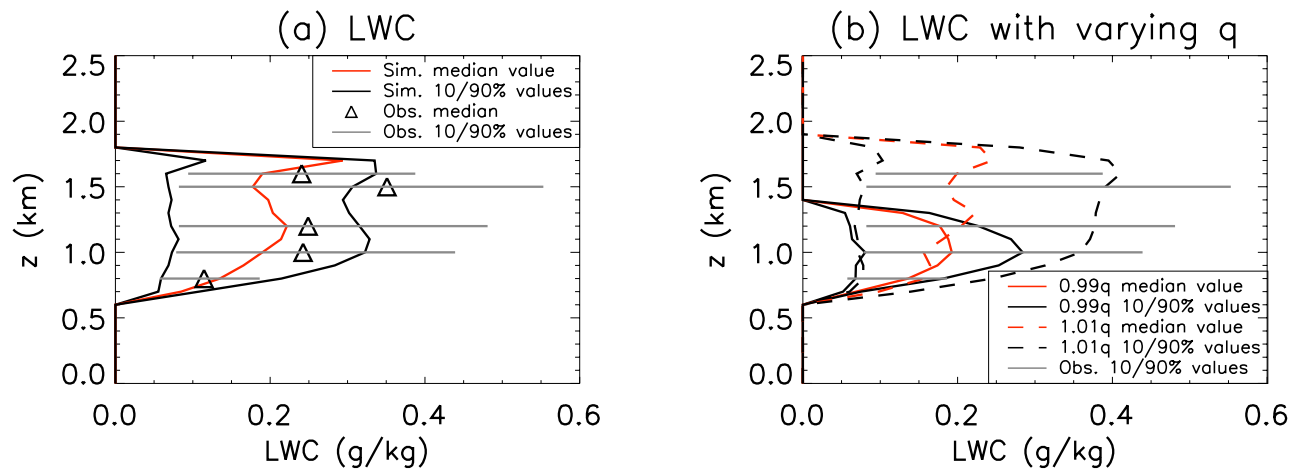

(c) Number conc.
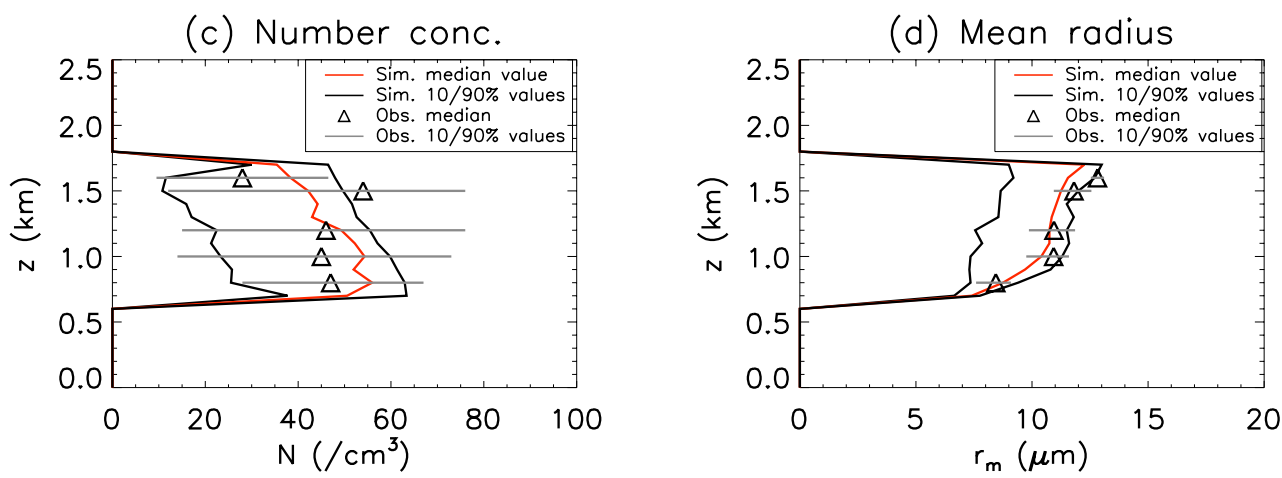

Fig. 2. Vertical profiles of the simulated (red) and observed (triangles) median values of (a) LWC, (c) droplet number concentration and (d) $r_{m}$ of the base case. Figure (b) shows vertical profiles of the median values of the LWC of the simulations with $99 \%$ and $101 \%$ of the specific humidity (respectively red solid and broken lines). Simulated 10 and $90 \%$ values are depicted with solid (broken) black lines. The horizontal grey lines through the triangles depict the observed range between the $10 \%$ and the $90 \%$ values.

Table 1. Parameters for the aerosol size distribution: aerosol concentration $\left(n, \mathrm{~cm}^{-3}\right)$, mean aerosol radius $\left(r_{m}, \mu \mathrm{m}\right)$ and standard deviation $(\sigma)$.

\begin{tabular}{cccc}
\hline Mode & $n\left(\mathrm{~cm}^{-3}\right)$ & $r_{m}(\mu \mathrm{m})$ & $\sigma$ \\
\hline 1 & 118 & 0.019 & 3.3 \\
2 & 11 & 0.056 & 1.6 \\
3 & 0.1 & 0.8 & 2.2 \\
\hline
\end{tabular}

simulations, with $99 \%$ and $101 \%$ of the original specific humidity, respectively. The results are shown in Fig. 2b. At lower humidity, the simulated cloud already dissipates below $1400 \mathrm{~m}$ and $90 \%$ values remain below $0.3 \mathrm{~g} / \mathrm{kg}$ throughout the cloud depth. A higher humidity does not result in an increase of the median LWC values, but the $90 \%$ values are raised from 0.34 to $0.4 \mathrm{~g} / \mathrm{kg}$. We conclude that varieties in humidity may partly account for the disagreement between observed and simulated range in the LWC, but do not explain the underestimation of the median values in the upper cloud areas by the model.

The increase of the $90 \%$ LWC values, after increasing the specific humidity, suggests that preprocessing of air at the cloud edge could also be of importance. In that case, entrained air is moistened, either by evaporation of cloud droplets at the cloud edge, or by detrained doplets outside of the cloud in a subsidizing shell (Heus and Jonker, 2008). Mixing this preprocessed air into the cloud core would result in a higher LWC in the cloud core than if dry environmental air is entrained. Due to the one-dimensionality of the model and assumed horizontal homogeneity, this process is not simulated.

We remark, that at altitudes just above cloud base the RICO data represent clouds characterized by a wide range of updraft velocities, whereas at higher altitudes only clouds with a more vigorous updraft are represented. The latter are characterized by relatively large LWC. This causes a deviation of the median LWC and its range towards higher values at higher levels, resulting in a discrepancy between simulated and observed values.

Simulated CDNC (Fig. 2c) is in the same order of magnitude as the observed CDNC. However, the model simulates a gradual decrease with height that is not observed. The aerosol scale height of $8000 \mathrm{~m}$ applied in our study only has a small influence on this. We suspect that the fact that the cloud ensemble represented in the RICO data is different for different altitudes, as mentioned above, also influences the 

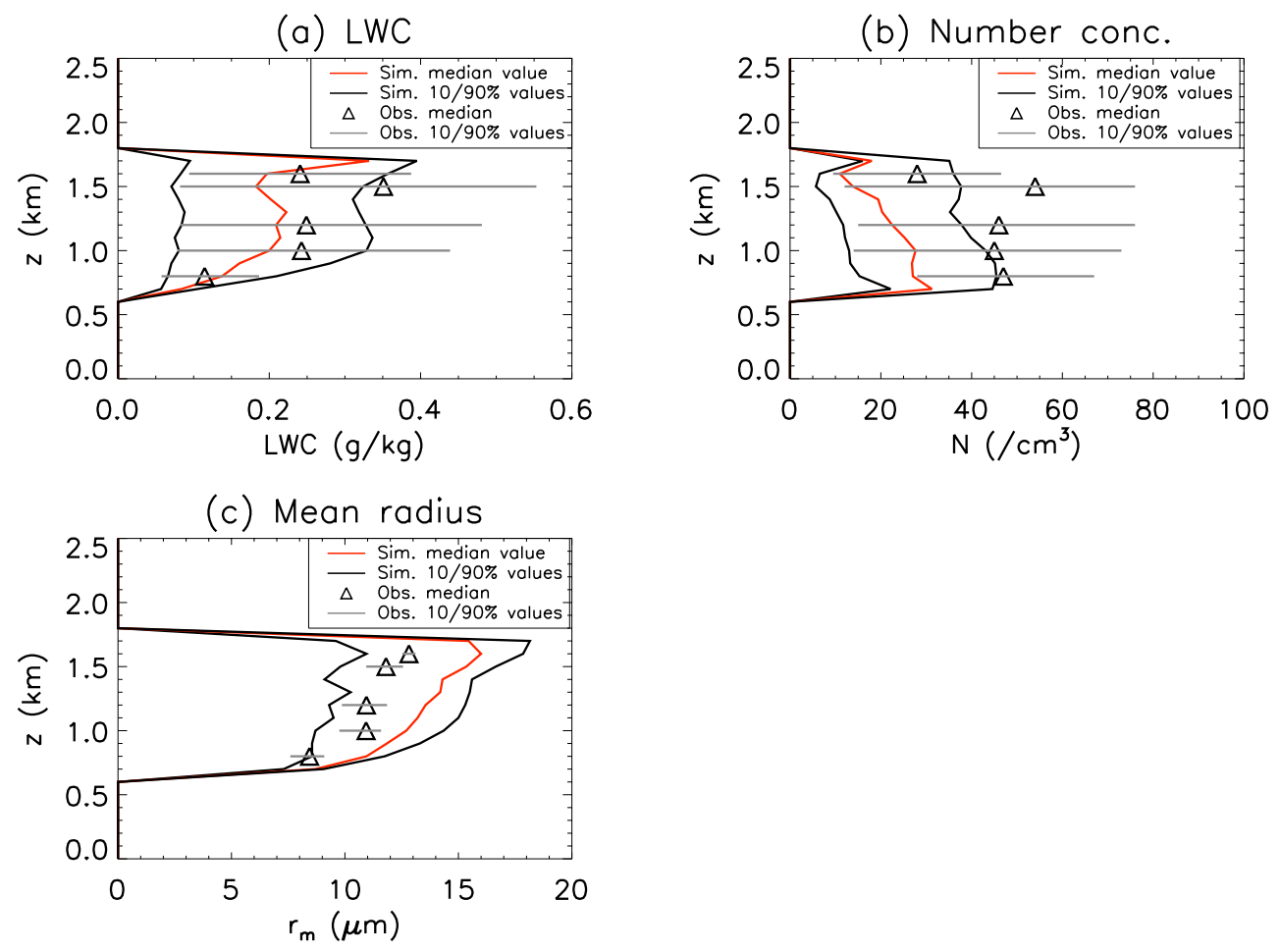

Fig. 3. As Fig. 2, but for the simulation without the presence of ambient CCN.

observed CDNC profiles. The range towards small concentrations is very well captured by the model. Towards high concentrations, the model underestimates the range increasingly with height, up to $35 \%$ at $1500 \mathrm{~m}$. Discrepancies between observed and simulated range in LWC and CDNC are probably associated, suggesting that more vigorous clouds, growing in more humid air and with relatively large CDNC caused by larger updraft velocities, have a relatively large weight within the observed data set.

In-cloud turbulence can lead to redistribution of droplets, resulting in higher local maxima of LWC and CDNC, although these fluctuations are on the $\mathrm{cm}$ scale and should average out at $1 \mathrm{~Hz}$ sampling frequency (Pinsky and Khain, 2003; Grits et al., 2006). However, for entrained eddies larger than $100 \mathrm{~m}$, the in-cloud variability is possibly large enough to sample at $1 \mathrm{~Hz}$ (Krueger et al., 1997), before it is being broken down by smaller-scale turbulence.

The simulated median values of $r_{m}$ shown in Fig. 2d, agree well with the observed median. An increase from 8 up to $11 \mu \mathrm{m}$ is simulated between 800 and $1000 \mathrm{~m}$ altitude, above which $r_{m}$ is nearly constant up to $1500 \mathrm{~m}$. In the cloud top, $r_{m}$ increases again, up to $12 \mu \mathrm{m}$, which is a slight underestimation compared to the observed increase up to $13 \mu \mathrm{m}$. A good agreement is found with the profile compiled by Arabas et al. (2009). The $10 \%$ percentile in the model is far too low compared to the observations. Closer inspection reveals that only during a small fraction of the cloud evolution such small mean radii are simulated, whereas such values are rare in the observations. This suggests that these small mean radii are a property of clouds in a very early (the first minute) stage or in the last moments of dissipation and have a low probability to be measured by aircraft.

To asses the influence of entrainment of ambient CCN into the cloud, we performed a simulation without ambient $\mathrm{CCN}$. Figure 3 shows the simulated profiles of LWC, CDNC and $r_{m}$.

Compared to the simulation with ambient $\mathrm{CCN}$, i.e. the base case, the LWC is highly similar, since LWC is governed by atmospheric dynamics. The median CDNC is smaller by nearly $50 \%$ at all heights. The reduction of CDNC is a direct consequence of the absence of ambient CCN. The median values of $r_{m}$ are overestimated, consistent with the underestimation of the CNDC.

The simulated total droplet size distributions (i.e. the sum of all the individual distributions considered by the model) at each level are averaged over the total simulation time, taking the conditions mentioned in Sect. 3 into account. In Fig. 4 the averaged size distribution of the simulations with and without the presence of ambient $\mathrm{CCN}$ is shown at each observed level. The figure also shows the observed 10\%/90\% range of droplet concentration as function of radius. This range reflects the variability of LWC and CDNC within the cloud ensemble, associated with e.g. humidity variation and differences in updraft velocity, as will be shown later. The 

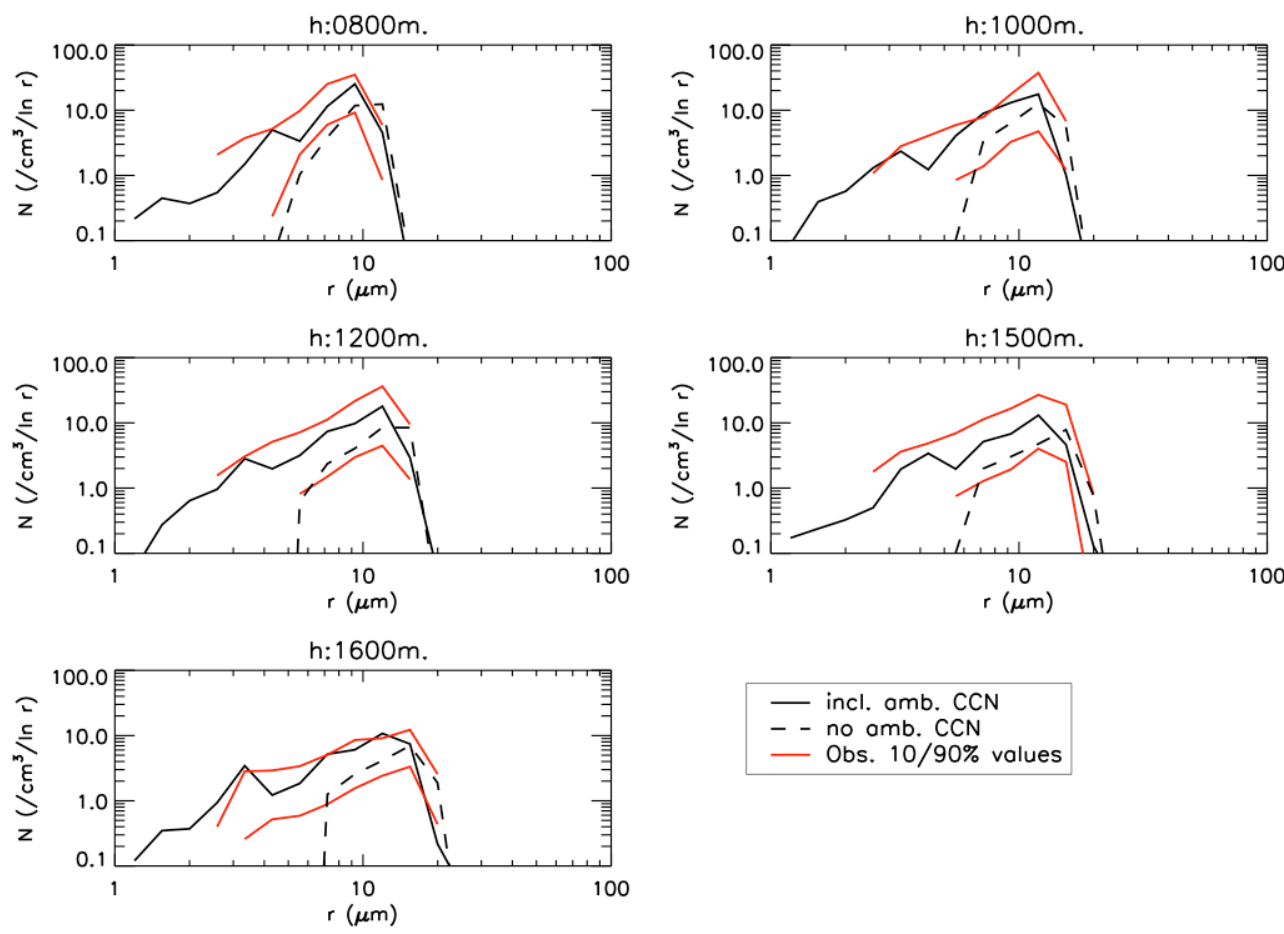

Fig. 4. Time averaged cloud droplet size distributions for: 800, 1000, 1200, 1500 and $1600 \mathrm{~m}$ altitude from the simulation with (solid) and without (broken) entrainment of ambient CCN. Red lines reflect the observed 10 and $90 \%$ values.

simulated spectra have been interpolated to a resolution consistent with the observations. The spectra simulated in the base case show good agreement with the observed range. The concentration maximum is located at approximately $8 \mu \mathrm{m}$ radius at $800 \mathrm{~m}$ and increases up to $12 \mu \mathrm{m}$ at $1500 \mathrm{~m}$, agreeing well with the observed peak. The gradual concentration decrease towards smaller droplet radii is consistent with the observed slope, as well as the rapid decrease towards larger radii. In the simulations where the initial specific humidity was varied with $1 \%$, as discussed previously, the slope of the droplet spectra is not altered significantly.

Analysis of the droplet spectra resulting from the simulation without ambient $\mathrm{CCN}$ further supports the occurrence of entrainment of fresh CCN. In this simulation, small droplets, $<5 \mu \mathrm{m}$ radius, are not present, and total droplet concentrations are relatively small compared to the observed range. The possibility that these droplets are initially present in the cloud column, but activate at higher altitudes under influence of a second saturation peak (Segal et al., 2003) is therefore excluded. It can be noticed that neglecting entrainment of $\mathrm{CCN}$ and the resulting increase of $r_{m}$ does not result in a significant increase of precipitable sized droplets for this case. To conclude, comparison of both simulations shows that entrainment of $\mathrm{CCN}$ into the cloud at higher altitudes, and subsequent activation to cloud droplets, is an important process in microphysical cloud evolution during RICO.
The concept of inhomogeneous mixing may lead to broadening of the droplet spectra, in addition of the effect of activation of entrained CCN (Su et al., 1998). They showed that discrete events of inhomogeneous mixing result in the presence of droplets with sizes continuous from 1 up to nearly $20 \mu \mathrm{m}$ for their case (Hawaiian trade cumuli). They also showed that superadiabatic droplet growth is possible via this mechanism. Their results agreed well with the observations. In our study, however, the ensemble of the droplet spectra is also represented well. The model simulates consistent slopes towards small and large droplets, compared with the observations. Therefore, we conclude that for this case, based on the droplet spectra, distinction can not be made between continuous homogeneous mixing and discrete inhomogeneous mixing.

\subsection{Role of entrainment and the initial vertical velocity}

In Fig. 5, the vertical profiles of the median values of the LWC, CDNC and $r_{m}$ are shown for simulations with two different values for the entrainment parameter $\alpha, 0.4$ and 0.2 , each with an initial vertical velocity, $w_{0}$, of $1.5 \mathrm{~m} / \mathrm{s}$ and of $1 \mathrm{~m} / \mathrm{s}$. The first column corresponds to the base case $(\alpha=0.40$; $w_{0}=1.5 \mathrm{~m} / \mathrm{s}$ ). The $\mathrm{LWC}$ profiles show that an $\alpha$ of 0.2 leads to an increase of cloud top height with $200 \mathrm{~m}$ compared to an $\alpha$ of 0.4. This is due to less efficient mixing of drier ambient air into the cloud (a direct result of the decrease of $\alpha$ ). A larger 


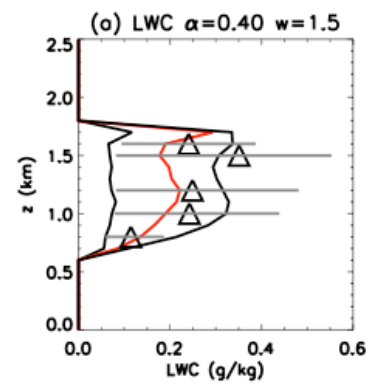

(e) Number conc.

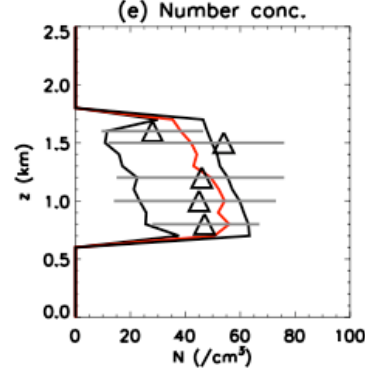

(i) Meon rodius

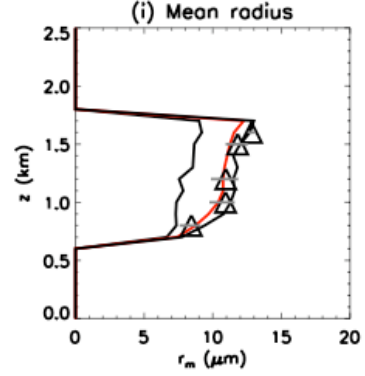

(b) LWC $\alpha=0.20 w=1.5$

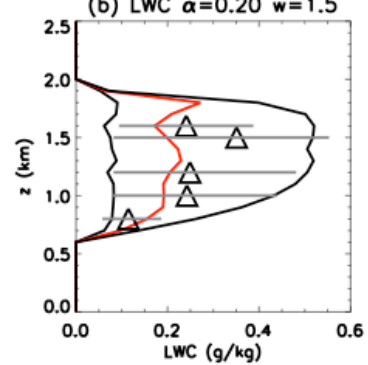

(f) Number conc.

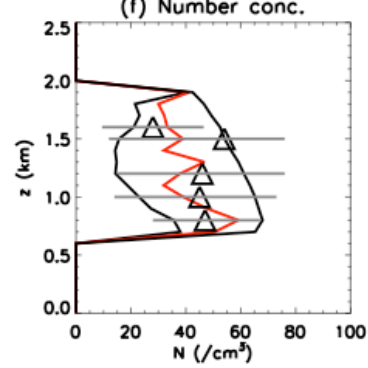

(j) Meon rodius

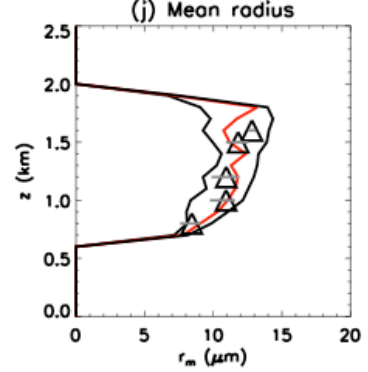

(c) LWC $\alpha=0.40 w=1$

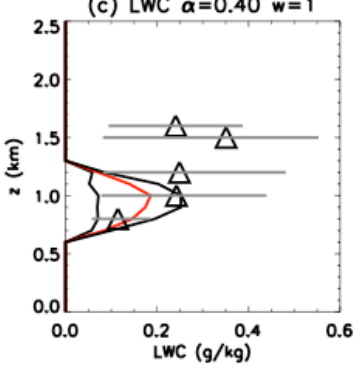

(g) Number conc.

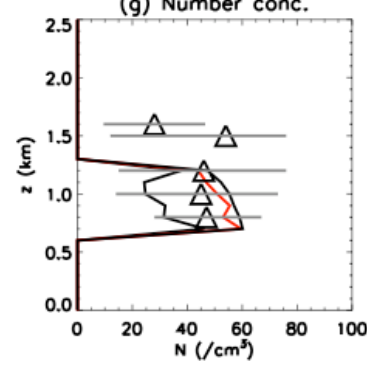

(k) Meon rodius

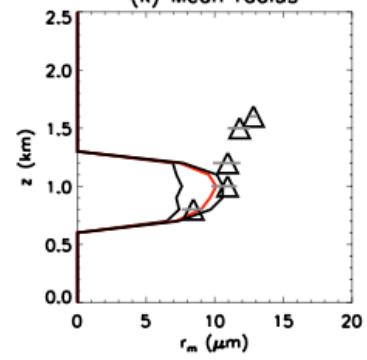

(d) LWC $\alpha=0.20 w=1$

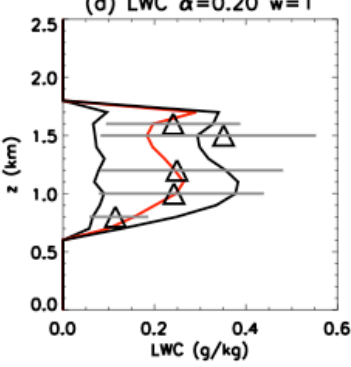

(h) Number conc.

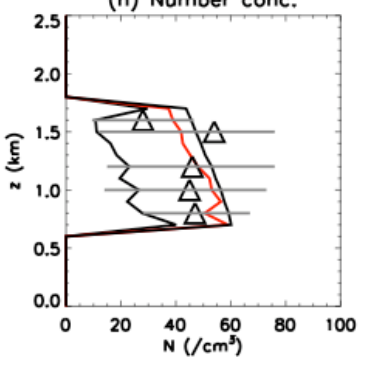

(1) Meon rodius

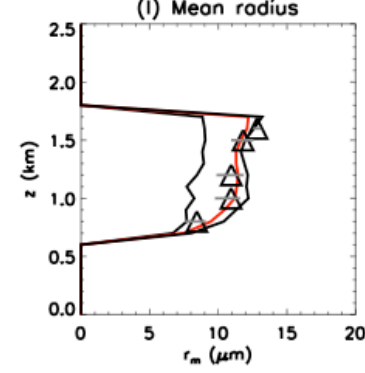

Fig. 5. As Fig. 2, but for four simulations: first column: base case, $\alpha=0.4, w_{0}=1.5 \mathrm{~m} / \mathrm{s}$; second column: $\alpha=0.2, w_{0}=1.5 \mathrm{~m} / \mathrm{s}$; third column $\alpha=0.4, w_{0}=1 \mathrm{~m} / \mathrm{s}$; fourth column: $\alpha=0.2, w_{0}=1 \mathrm{~m} / \mathrm{s}$.

part of the released latent heat is used for rising motion and less colder ambient air is entrained. Also the updraft velocities are different, with a maximum value of $2.6 \mathrm{~m} / \mathrm{s}$ for the simulation with $\alpha=0.2$, and $1.8 \mathrm{~m} / \mathrm{s}$ during the $\alpha=0.40$ simulation. Although the median of both simulations are similar, the range in simulated LWC for $\alpha=0.2$ is larger, especially above $1000 \mathrm{~m}$, in better agreement with the observed ranges.

For $\alpha=0.4$ and $w_{0}=1 \mathrm{~m} / \mathrm{s}$, the simulated cloud top altitude is lower than the base case, i.e. $1200 \mathrm{~m}$. Further, the LWC remains smaller and the cloud dissipates earlier through mixing with the environment. Therefore, the cloud top does not reach the levels with enhanced environmental RH, which explains the absence of the secondary peak in LWC below cloud top. If $\alpha$ is also decreased to 0.2 , the cloud top reaches $1700 \mathrm{~m}$. In this case, the simulated and observed median LWC are similar for the lower three observed levels. Just as for the base case and when $w_{0}=1.5 \mathrm{~m} / \mathrm{s}$, the model predicts a minimum in the LWC at $1500 \mathrm{~m}$ and a maximum just below the cloud top.

For all simulations, the $10 \%$ and median values for CDNC are more or less the same and agree with the observations.
The simulations initialized with $w_{0}=1.5 \mathrm{~m} / \mathrm{s}$ display a CDNC range up to $65 \mathrm{~cm}^{-3}$, which is somewhat larger than the simulations initialized with $w_{0}=1 \mathrm{~m} / \mathrm{s}$. This reflects the increase of the cutoff radius of activated aerosol with decreasing $w_{0}$.

Decreasing $\alpha$ does not change the range and median values of $r_{m}$, but the $10 \%$ and $90 \%$ values are shifted towards larger radii, such that the median values more or less are in the centre. Decreasing $w_{0}$ does affect the median and $90 \%$ values. Both are slightly smaller, $0.5-1 \mu \mathrm{m}$ at $1000 \mathrm{~m}$ altitude. Decreasing both values does not affect the $10 \%$ values, but up to $1500 \mathrm{~m}$ both median and $90 \%$ values have increased with $0.5-1 \mu \mathrm{m}$ and above only the median value has increased with $0.5 \mu \mathrm{m}$, nearly overlapping the observed median values throughout the cloud.

Recapitulating, the entrainment efficiency appears not to influence the median LWC very much, but the occurrence of parcels with relatively high LWC increases. On the other hand, the initial vertical velocity appears to be the dominant influence on the cloud vertical extent and lifetime. It has a large impact on the occurrence of cloud parcels with relatively large LWC, CDNC and cloud drop radius. 
Figure 6 shows simulated droplet spectra at $1000 \mathrm{~m}$ altitude for each scenario. All three variations display a good agreement with the base case, with concentration maxima at 10-11 $\mu \mathrm{m}$. Largest differences between the droplet spectra are at radii smaller than $5 \mu \mathrm{m}$, which reflects the changes in entrainment with changing values for the parameters $\alpha$ and $w_{0}$. The different simulations result in droplet peaks at slightly differing radii between $2-3 \mu \mathrm{m}$, which agrees relatively well with individual observed droplet spectra (not shown). Generally, the simulated distributions are all within the observed variability. Previously it is shown that variations of the entrainment parameter and the initial vertical velocity do not affect profiles of CDNC and droplet radius to a large extent (see Fig. 5), and Fig. 6 shows that the same conclusion is valid for the droplet spectra. This is associated with the nearly constant aerosol concentration vertical profile in the boundary layer during RICO. For such conditions, the changes in droplet concentrations due to detrainment and entrainment appear to balance more or less, and this precludes an accurate assessment of the actual entrainment strength. A larger impact of the entrainment efficiency on CDNC and cloud drop spectra may be expected for steeper aerosol profiles so that the entrained air at higher cloud altitudes has much smaller particle concentrations than air at the cloud base.

In stratus/stratocumulus clouds, spectral broadening of cloud droplets has been associated with variations in updraft velocity at cloud base (Hudson and Yum, 1997; Erlick et al., 2005). In our study of trade-wind cumuli with lateral entrainment, we find that droplet spectra are relatively insensitive for small variations in $w_{0}$ and $\alpha$.

In summary, the simulations presented here, including those with varying humidity, are well within the observed ranges and reflect, at least partly, the different clouds that make up the RICO ensemble. This supports the idea that this ensemble reflects clouds in different growth stages and growing in varying dynamical conditions associated with spatial variability in atmospheric humidity.

\section{Conclusions}

With a 1-D-cloud column model with detailed calculation of aerosol activation and condensation/evaporation processes, we simulated a trade wind cumulus cloud as observed during RICO (Rain in Cumulus over the Ocean campaign). The simulation reproduces observed profiles of LWC. Simulated $\mathrm{CDNC}$ and mean cloud drop radius agree relatively well with observations. The main discrepancies are an underestimation of LWC below the cloud top, and a slight decrease of CDNC with altitude that is not observed. Discrepancies between model results and observations may partly be explained by spatial humidity variations and by the fact that the observations reflect an ensemble of clouds with different updraft velocities, LWC and vertical extent, whereas our simulation

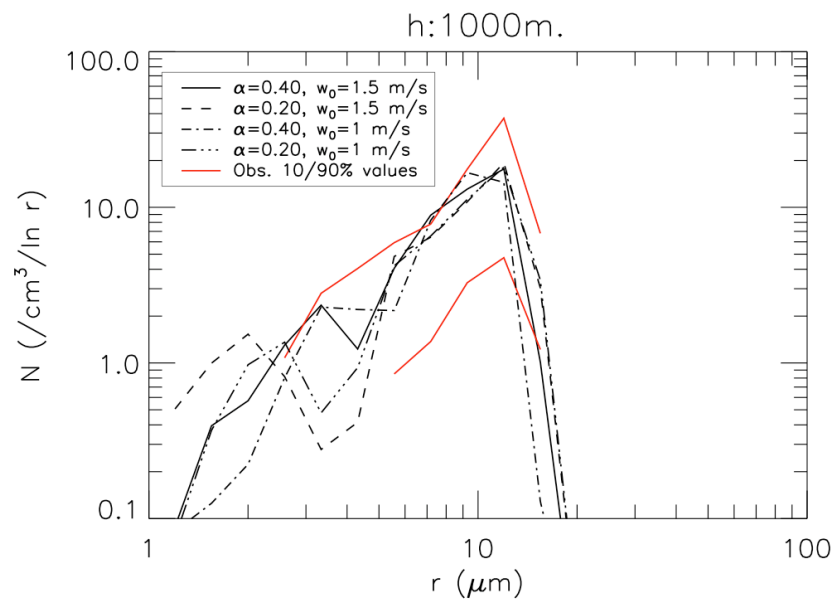

Fig. 6. Time averaged cloud droplet size distributions at $1000 \mathrm{~m}$ height for four simulations: base case (solid black line), $\alpha=0.2$ and $w_{0}=1.5 \mathrm{~m} / \mathrm{s}$ (dashed line), $\alpha=0.4$ and $w_{0}=1 \mathrm{~m} / \mathrm{s}$ (dot-dashed line) and $\alpha=0.2$ and $w_{0}=1 \mathrm{~m} / \mathrm{s}$ (dot-dot-dashed-line). In red are the 10 and $90 \%$ values from the observations.

pertains to a single cloud. It is possible that at higher cloud altitudes the observations are biased towards relatively vigorous cumuli with high updraft velocities and CDNC. This also explains the smaller range of simulated LWC and CDNC, with underestimation of the relative occurrence of higher values.

Observed cloud droplet spectra are reproduced well by the model. Simulated and observed maximum concentrations are located at similar droplet radii and simulation shows a gentle slope of the droplet concentration towards smaller radii and a steeper slope towards larger radii, as found in the observations.

We demonstrated that the slope towards small radii is directly associated with the continuous entrainment and subsequent activation of ambient aerosol. Thus, entrainment exerts a significant influence on the droplet size distribution width. It is therefore a crucial factor for the precipitation formation efficiency and optical properties of the cloud. Preliminary results of optical thickness calculations indicate that compared to the base case, cloud optical thickness decreases with $17 \%$ (17.5 vs. 14.5) if increase of CDNC due to entrainment of ambient $\mathrm{CCN}$ is not considered. The exchange between cloudy air and environmental air, including the activated and unactivated aerosol particles, must therefore be represented realistically in atmospheric models aimed to study indirect aerosol effects. Further, due to entrainment of aerosol into clouds more particles will be subject to cloud processing (e.g., Roelofs and Kamphuis, 2009) which is relevant for the aerosol direct effect.

When the model is initialized with a smaller initial vertical velocity, all simulated clouds have lower cloud tops and 
lower LWC maxima. This is consistent with the observations that show that larger vertical velocities are associated with larger LWC.

The entrainment parameter $\alpha$ influences the dynamical evolution of the simulated cloud, as expressed in LWC and cloud top height. CDNC is only marginally influenced by $\alpha$. Particle concentrations inside and outside the cloud are almost equal, so that the in-cloud CCN population is relatively insensitive to the exchange between cloudy and ambient air. It depends on the supersaturation how many of the entrained $\mathrm{CCN}$ activate. We found that more subsaturated air is mixed into the cloud when entrainment is more efficient, and this has a negative feedback on the supersaturation. At lower supersaturation values, the cut-off radius is larger and a smaller fraction of the entrained $\mathrm{CCN}$ is activated than for less efficient entrainment. A smaller supersaturation also results in less efficient condensation of water vapor and, hence, smaller latent heat release and updraft velocities. Mixing also has a direct negative feedback on the vertical velocity, because the entrained air is at rest and slightly colder than the cloud air. This feeds back on the supersaturation and the entrainment rate. We conclude that the feedbacks between the vertical motion, supersaturation and the entrainment rate appear to cause a relative balance in cloud growth for the conditions typical of RICO, i.e., a well-mixed boundary layer capped by an inversion.

Acknowledgements. Data provided by NCAR/EOL under sponsorship of the National Science Foundation http://data.eol.ucar.edu/.

Edited by: P. Spichtinger

\section{References}

Albrecht, B. A.: Aerosols, cloud microphysics, and fractional cloudiness, Science, 245, 1227-1230, 1989.

Arabas, S., Pawlowska, H., and Grabowski, W. W.: Effective radius and droplet spectral width from in-situ aircraft observations in trade-wind cumuli during RICO, Geophys. Res. Lett., 36, L11803, doi:10.1029/2009GL038257, 2009.

Blyth, A. M. and Latham, J.: Airborne studies of the altitudinal variability of the microphysical structure of small, ice-free, Montanan cumulus clouds, Q. J. Roy. Meteor. Soc., 116, 1405-1423, doi:10.1002/qj.49711649608, 1990.

Burnet, F. and Brenguier, J.-L.: Observational study of the entrainment-mixing process in warm convective clouds, J. Atmos. Sci., 64, 1995-2011, 2007.

Charlson, R. J., Schwarz, S. E., Hales, J. M., Cess, R. D., Coakley Jr., J. A., Hansen, J. E., and Hofmann, D. J.: Climate forcing by anthropogenic aerosols, Science, 255, 423-430, 1992.

Erlick, C., Khain, A., Pinksy, M., and Segal, Y.: The effect of wind velocity fluctuations on drop spectrum broadening in stratocumulus clouds, Atmos. Res., 75, 15-45, doi:10.1016/j.atmosres.2004.10.007, 2005.

Fountoukis, C. and Nenes, A.: Continued development of a cloud droplet formation parameterization for global climate models, J. Geophys. Res., 110, D11212, doi:10.1029/2004JD005591, 2005.
Gerber, H., Frick, G., Malinowski, S. P., Brenguier, J.-L., and Burnet, F.: Holes and entrainment in stratocumulus, J. Atmos. Sci., 62, 443-459, 2005.

Gerber, H., Frick, G., Jensen, J. B., and Hudson, J. G.: Entrainment, mixing and microphysics in trade-wind cumulus, J. Meteorol. Soc. Jpn., 86A, 87-106, 2008.

Grits, B., Pinsky, M., and Khain, A.: Investigation of small-scale droplet concentration inhomogeneities in a turbulent flow, Meteorol. Atmos. Phys., 92, 191-204, doi:10.1007/s00703-005-01574, 2006.

Hänel, G.: The role of aerosol properties during the condensational stage of cloud: A reinvestigation of numerics and microphysics, Beitr. Phys. Atmosph., 60, 321-339, 1987.

Heus, T. and Jonker, H. J. J.: Subsiding shells around shallow cumulus clouds, J. Atmos. Sci., 65, 1003-1018, doi:10.1175/2007JAS2322.1, 2008.

Heus, T., van Dijk, G., Jonker, H. J. J., and van der Akker, H. E. A.: Mixing in shallow cumulus clouds studied by lagrangian particle tracking, J. Atmos. Sci., 65, 2581-2597, doi:10.1175/2008JAS2572.1, 2008.

Hicks, E., Pontikis, C., and Rigaud, A.: Entrainment and mixing processes as related to droplet growth in warm midlatitude and tropical clouds, J. Atmos. Sci., 47, 1589-1618, 1990.

Holland, J. Z. and Rasmusson, E. M.: Measurement of atmospheric mass, energy, and momentum budgets over a 500-kilometer square of tropical ocean, Mon. Weather Rev., 101, 44-55, 1973.

Hudson, J. G. and Mishra, S.: Relationship between CCN and cloud microphysics variations in clean maritime air, Geophys. Res. Lett., 34, L16804, doi:10.1029/2007GL030044, 2007.

Hudson, J. G. and Yum, S. S.: Droplet spectral broadening in Marine Stratus, J. Atmos. Sci., 54, 2642-2654, 1997.

Jacobson, M. Z.: Fundamentals of Atmospheric Modeling, Cambridge Univ. Press, New York, 1998.

Kreidenweis, S., Walcek, C., Feingold, G., Gong, W., Jacobson, M., Kim, C., Liu, X., Penner, J., Nenes, A., and Seinfeld, J.: Modification of aerosol mass and size distribution due to aqueous phase SO2 oxidation in clouds: Comparisons of several models, J. Geophys. Res., 108, 4213, doi:10.1029/2002JD002697, 2003.

Krueger, S. K., Su, C.-W., and McMurtry, P. A.: Modeling entrainment and finescale mixing in cumulus clouds, J. Atmos. Sci., 54, 2697-2712, 1997.

Kulmala, M., Laaksonen, A., Korhonen, P., Ahonen, T., and Baret, J.: The effect of atmospheric nitric acid vapor on cloud condensation nucleus activation, J. Geophys. Res., 98, 22949-22958, 1993.

Lee, S. S., Donner, L. J., Phillips, V. T. J., and Ming, Y.: The dependence of aerosol effects on clouds and precipitation on cloudsystem organization, shear and stability, J. Geophys. Res., 113, D16202, doi:10.1029/2007JD009224, 2008.

Leroy, D., Wobrock, W., and Flossmann, A. I.: On the influence of the treatment of aerosol particles in different bin microphysical models: A comparison between two different schemes, Atmos. Res., 85, 269-287, doi:10.1016/j.atmosres.2007.01.003, 2007.

Leroy, D., Wobrock, W., and Flossmann, A. I.: The role of boundary layer aerosol particles for the development of deep convective cloud: A high-reolution 3D model with detailed (bin) microphysics applied to CRYSTAL-FACE, Atmos. Res., 91, 62-78, doi:10.1016/j.atmosres.2008.06.001, 2009.

Lohmann, U. and Feichter, J.: Global indirect aerosol effects: a 
review, Atmos. Chem. Phys., 5, 715-737, 2005,

http://www.atmos-chem-phys.net/5/715/2005/.

Lu, M.-L., Wang, J., Freedman, A., Jonsson, H. H., Flagan, R. C., McClatchey, R. A., and Seinfeld, J. H.: Analysis of humidity halos around trade wind cumulus clouds, J. Atmos. Sci., 60, 10411059, 2003.

Meskhidze, N., Nenes, A., Conant, W. C., and Seinfeld, J. H.: Evolution of a new cloud droplet activation parameterization with in situ data from CRYSTAL-FACE and CSTRIPE, J. Geophys. Res., 110, D16202, doi:10.1029/2004JD005703, 2005.

Ogura, Y. and Takahashi, T.: Numerical simulation of the life cycle of a thunderstorm cell, Mon. Weather Rev., 99, 895-911, 1971.

Paluch, I. R.: The entrainment mechanism in Colorado cumuli, J. Atmos. Sci., 36, 2467-2478, 1979.

Paluch, I. R.: Mixing and the cloud droplet size spectrum: Generalizations from the CCOPE data, J. Atmos. Sci., 43, 1984-1993, 1986.

Penner, J. E. and Chuang, C. C.: The role of entrainment and mixing in altering the relationship between aerosol concentration and cloud drop number concentration, Ninth ARM Science Team Meeting Proceedings, 1999.

Peter, J. R., Blyth, A. M., Brooks, B., McQuaid, J. B., Lingard, J. J. N., and Smith, M. H.: On the composition of Caribbean maritime aerosol particles measured during RICO, Q. J. Roy. Meteor. Soc., 134, 1059-1063, doi:10.1002/qj.198, 2008.

Pinsky, M. and Khain, A.: Fine structure of cloud droplet concentrations as seen from the fast-FSSP measurements. Part II: Results of in situ observations, J. Appl. Meteorol., 42(1), 65-73, 2003.

Pruppacher, H. R. and Klett, J. D.: Microphysics of clouds and precipitation, D. Reidel, Dordrecht, 1978.

Raga, G. B., Jensen, J. B., and Baker, M. B.: Characteristics of cumulus band clouds off the coast of Hawaii, J. Atmos. Sci., 47, 338-355, 1990.

Rauber, R., Stevens, B., Ochs, H., Knight, C., Albrecht, B., Blyth, A., Fairall, C., Jensen, J., Lasher-Trapp, S., Mayol-Bracero, O., Vali, G., Anderson, J., Baker, B., Bandy, A., Burnet, E., Brenguier, J., Brewer, W., Brown, P., Chuang, P., Cotton, W., Girolamo, L. D., Geerts, B., Gerber, H., Gške, S., Gomes, L., Heikes, B., Hudson, J., Kollias, P., Lawson, R., Krueger, S., Lenschow, D., Nuijens, L., O'Sullivan, D., Rilling, R., Rogers, D., Siebesma, A., Snodgrass, E., Stith, J., Thornton, D., Tucker, S., Twohy, C., and Zuidema, P.: Rain In Shallow Cumulus over the Ocean: The RICO Campaign, B. Am. Meteorol. Soc., 88, 1912-1928, 2007.

Roelofs, G.-J. and Jongen, S.: A model study of the influence of aerosol size and chemical properties on precipitation formation in warm clouds, J. Geophys. Res., 109, D22201, doi:10.1029/2004JD004779, 2004.
Roelofs, G.-J. and Kamphuis, V.: Cloud processing, cloud evaporation and Angström exponent, Atmos. Chem. Phys., 9, 71-80, 2009, http://www.atmos-chem-phys.net/9/71/2009/.

Roesner, S., Flossmann, A. I., and Pruppacher, H. R.: The effect on the evolution of the drop spectrum in clouds of the preconditioning of air by successive convective elements, Q. J. Roy. Meteor. Soc., 116, 1389-1403, doi:10.1002/qj.49711649607, 1990.

Segal, Y., Pinsky, M., Khain, A., and Erlick, C.: Thermodynamic factors influencing bimodal spectrum formation in cumulus clouds, Atmos. Res., 66, 43-64, 2003.

Siebesma, A. P. and Cuijpers, J. W. M.: Evaluation of parametric assumptions for shallow cumulus convection, J. Atmos. Sci., 52, 650-666, 1995.

Siebesma, A. P., Bretherton, C. S., Brown, A., Chlond, A., Cuxart, J., Duynkerke, P. G., Jiang, H., Khairoutdinov, M., Lewellen, D., Moeng, C.-H., Sanchez, E., Stevens, B., and Stevens, D. E.: A large eddy simulation intercomparison study of shallow cumulus convection, J. Atmos. Sci., 60, 1201-1219, 2003.

Solomon, S., Qin, D., Manning, M., Alley, R. B., Berntsen, T., Bindoff, N. L., Chen, Z., Chidthaisong, A., Gregory, J. M., Hegerl, G. C., Heimann, H., Hewitson, B., Hoskins, B. J., Joos, F., Jouzel, J., Kattsov, V., Lohmann, U., Matsuno, T., Molina, M., Nichollsand, N., Overpeck, J., Raga, G., Ramaswamy, V., Ren, J., Rusticucci, M., Somerville, R., Stocker, T. F., Whetton, P. A. W. R., and Wratt, D.: Technical Summary, in: Climate Change 2007: The Physical Science Basis. Contribution of Working Group I to the Fourth Assessment Report of the Intergovernmental Panel on Climate Change, Cambridge Univ. Press, Cambridge, United Kingdom and New York, NY, USA, 2007.

Stevens, B., Ackerman, A. S., Albrecht, B. A., Brown, A. R., Chlond, A., Cuxart, J., Duynkerke, P. G., Lewellen, D. C., Macvean, M. K., Neggers, R. A. J., Sanchez, E., Siebesma, A. P., and Stevens, D. E.: Simulation of trade wind cumuli under a strong inversion, J. Atmos. Sci., 58, 1870-1891, 2001.

Su, C.-W., Krueger, S. K., McMurtry, P. A., and Austin, P. H.: Linear eddy modeling of droplet spectral evolution during entrainment and mixing in cumulus clouds, Atmos. Res., 47-48, 41-58, 1998.

Takahashi, T.: Warm rain, giant nuclei and chemical balance - a numerical model, J. Atmos. Sci., 33, 269-286, 1976.

Twomey, S.: The influence of pollution on the shortwave albedo of clouds, J. Atmos. Sci., 34, 1149-1154, 1977.

Warner, J.: On steady-state one-dimensional models of cumulus convection, J. Atmos. Sci., 27, 1035-1040, 1970. 